\title{
Feasibility of Transient Elastography with M and XL probes in real life
}

\section{Ioan Sporea, Roxana Șirli, Ruxandra Mare, Alina Popescu, Siegfried Cristian Ivașcu}

Department of Gastroenterology and Hepatology, "Victor Babeş” University of Medicine and Pharmacy Timişoara, Romania

\begin{abstract}
Aim: Reliable liver stiffness measurements (RLSM) using Transient Elastography (TE) with the standard M probe are difficult to obtain in overweight $\left(\mathrm{BMI} \geq 25 \mathrm{~kg} / \mathrm{m}^{2}\right)$ and obese $\left(\mathrm{BMI}>30 \mathrm{~kg} / \mathrm{m}^{2}\right)$ patients. The aim of our paper was to assess the feasibility of TE in daily practice using both M and XL probes. Material and method: We studied retrospectively 3235 patients with chronic liver disease assessed by TE first by the M probe (standard probe - transducer frequency $3.5 \mathrm{MHz}$ ), and if the measurements were unreliable, with the XL probe (transducer frequency $2.5 \mathrm{MHz}$ ). Reliable measurements were defined as the median of 10 valid measurements with a success rate $\geq 60 \%$ and an interquartile range $<30 \%$. Results of liver elasticity were expressed in kiloPascals $(\mathrm{kPa})$. Results: RLSM by M probe were obtained in $62.2 \%(2015 / 3235)$ patients, and by XL probe in 1011/1220 (80\%) of patients with unreliable measurements by M probe; thus we obtained RLSM in $93.5 \%$ of 3235 cases.

In overweight patients we obtained RLSM in $89.9 \%(1039 / 1156)$ cases: in $63.1 \%$ (729) by M probe and in 26.8\% (310) by XL probe. In obese patients we obtained RLSM in 83.8\% (746/890): in 18.4\% (164) by M probe and in $65.4 \%$ (582) by XL probe. Thus, by using both probes, RLSM were obtained in 1785 (87.2\%) of overweight and obese patients. Conclusion: The feasibility of the M probe was $62.2 \%$ in our Department. Reliable measurements using M or XL probe allowed the evaluation of liver stiffness in $93.5 \%$ of cases. By using both M and XL probes, reliable LSM by TE can be obtained in the majority of obese and overweight patients $(87.2 \%)$.
\end{abstract}

Keywords: Transient Elastography, liver stiffness, feasibility, overweight, obese, real life

\section{Introduction}

Considering liver biopsy an invasive procedure, many patients with chronic liver diseases prefer to choose a noninvasive method for the assessment of liver fibrosis. For many years, as proven by meta-analyses, Transient Elastography (TE) has been considered to be a standard noninvasive procedure for liver fibrosis evaluation [1-4]. This procedure is performed in less than 5 minutes, is painless, repeatable and well accepted by patients. In many European centers, introduction of TE has led to a decrease in the need for liver biopsies performed for the assessment of

Received 01.11.2015 Accepted 05.12.2016

Med Ultrason

2016, Vol. 18, No 1, 7-10

Corresponding author: Roxana Șirli, $\mathrm{MD}, \mathrm{PhD}$

14 , Sirius Str, ap. 5 ,

300688 Timişoara, Romania

Phone: +40748331232

Fax: +40256488003

E-mail: roxanasirli@gmail.com chronic liver diseases $[5,6]$. This is due to patients' preference, but also to the fact that TE is accepted by physicians and international guidelines [7] as a reliable tool for diagnosing significant fibrosis.

But what are the criticisms of this method? It can discriminate well enough between mild and severe fibrosis [1-4], but it cannot discriminate between successive stages of fibrosis. Especially absent and mild fibrosis are difficult to differentiate, since an overlap between values has been observed. Maybe the most important drawback is the method's feasibility. Castera et al was the first to show in a very large cohort of patients, that valid measurements can be obtained in only approximately $85 \%$ of cases by a standard $\mathrm{M}$ probe [8]. In a more recent study, Șirli et al evaluated the real-life feasibility of TE by a standard M probe, and found that valid measurements can be obtained in approximately $70 \%$ of cases [9]. However, the population evaluated in this study had a higher mean body mass index (BMI) as compared with the French population evaluated by Castera et al [8], hence a poorer feasibility. 
Reliable measurements in TE are defined as median value of 10 valid LSM with a success rate (SR) $\geq 60 \%$ and an interquartile range interval (IQR) $<30 \%[10,11]$. Unreliable TE measurements were considered the following situations: fewer than 10 valid shots, $\mathrm{SR}<60 \%$ and/or IQR $\geq 30 \%[8,12]$. In large studies the rate of reliable measurements with the $\mathrm{M}$ probe, the "intent to diagnose", was reported to be $70 \%$ [9] and $85 \%$ [8], which is not enough for daily practice! This is why the producer of the FibroScan device (EchoSens, Paris, France) developed the XL probe to be used in overweight and obese patients. By decreasing the frequency of the probe to $2.5 \mathrm{MHz}$ as compared with $3.5 \mathrm{MHz}$ in the standard $\mathrm{M}$ probe, the penetration of ultrasound waves increases, and thus the method's feasibility increases [13].

In real life, the prevalence of overweight (Body Mass Index - BMI $\left.\geq 25 \mathrm{~kg} / \mathrm{m}^{2}\right)$ and obese $\left(\mathrm{BMI} \geq 30 \mathrm{~kg} / \mathrm{m}^{2}\right)$ patients is increasing in all developed countries [14]. On the other hand, diabetes mellitus and hypertriglyceridemia are common diseases in the civilized world. These are the main causes of non-alcoholic fatty liver diseases (NAFLD) and, in a proportion of subjects, of non-alcoholic steatohepatitis (NASH) that can progress to liver fibrosis and cirrhosis. The assessment of liver fibrosis in NASH patients is very important for prognosis, but it can be difficult by TE with the $\mathrm{M}$ probe, since many of them are overweight and obese.

The aim of our study was to evaluate the feasibility of Transient Elastography in daily practice, using both standard $\mathrm{M}$ and XL probes, and the feasibility of TE in overweight and obese patients.

\section{Material and method}

\section{Patients and liver stiffness measurements}

Our retrospective study included 3235 patients with chronic liver disease (chronic hepatitis $\mathrm{C}$, chronic hepatitis $\mathrm{B}$, alcoholic steatohepatitis - ASH, NASH, primary biliary cirrhosis, autoimmune hepatitis, etc.) referred to our Department to assess liver fibrosis by TE between January 2012 - October 2014. In all these patients liver stiffness measurements (LSM) were made by Transient Elastography, using a FibroScan ${ }^{\circledR}$ device (EchoSens, Paris, France). After informed consent was obtained, in each patient measurements were made with the $\mathrm{M}$ probe (standard probe transducer frequency $3.5 \mathrm{MHz}$ ) or XL probe (transducer frequency $2.5 \mathrm{MHz}$ ). In all patients the $\mathrm{M}$ probe was used first, and if the results were unreliable we used the XL probe. The measurements were made in fasting patients laing in dorsal decubitus with the right arm in maximal abduction. The tip of the probe, covered with coupling gel, was placed on the skin between the ribs aiming at the right liver lobe. The operator, assisted by ultrasound time-motion and A-mode images provided by the system, located a portion of the liver at least $6 \mathrm{~cm}$ thick and free of large vascular structures. Once the area of measurement had been located, the operator pressed the probe button to begin an acquisition. Measurements which did not have a correct vibration shape or a correct follow up of the vibration propagation were automatically rejected by the software and considered as invalid measurements.

Ten valid LSM were acquired with each probe, a median was calculated expressed in kiloPascals $(\mathrm{kPa})$. Reliable LS measurements were defined as median of 10 valid measurements with a success rate $(\mathrm{SR}=$ ratio of the number of successful acquisitions divided by the total number of acquisitions) $\geq 60 \%$ and an interquartile range $(\mathrm{IQR}=$ the range of the middle $50 \%$ of the data) $<30 \%$. TE measurements were considered unreliable in the following situations: fewer than 10 valid shots, $\mathrm{SR}<60 \%$ and $/$ or $\mathrm{IQR} \geq 30 \%$.

All patients signed the informed consent to be evaluated by TE; the study was approved by the local Ethics Committee and was in accordance with the Helsinki Declaration of 1975.

\section{Statistical analysis}

The statistical analysis was performed using Microsoft Office Excel 2007 (Microsoft Corporation Redmond, Washington, USA) and GraphPad Prism 6 Program (GraphPad Software Inc, La Jolla, California, USA). Differences between numerical variables were analyzed by the Wilcoxon paired $t$ test. Qualitative variables were presented as numbers and percentages. The Chi-square (X2) test (with Yates' correction for continuity) was used for the comparison of two proportions expressed as a percentage. A p-value less than 0.05 was regarded as significant for each statistical test.

\section{Results}

\section{Patients}

The studied group included 3235 patients with an average BMI of $28 \pm 4.9 \mathrm{~kg} / \mathrm{m}^{2}: 1189$ normal weight (BMI $\left.<25 \mathrm{~kg} / \mathrm{m}^{2}\right), 1156$ overweight (BMI $25-30 \mathrm{~kg} / \mathrm{m}^{2}$ ) and 890 obese $\left(\mathrm{BMI}>30 \mathrm{~kg} / \mathrm{m}^{2}\right)$. Patients' characteristics are presented in Table 1.

\section{Liver stiffness measurements}

Valid measurements were obtained by the $\mathrm{M}$ probe in 2015 patients $(62.2 \%)$ with an average BMI of 26.1 $\mathrm{kg} / \mathrm{m}^{2}$. The average BMI of the patients evaluated with XL probe was $31.3 \mathrm{~kg} / \mathrm{m}^{2}$, significantly higher than in patients who could be evaluated by M probe $(\mathrm{p}<0.0001)$. Of the 1220 patients with unreliable results with $\mathrm{M}$ probe, valid measurements were obtained with XL probe in 1011 patients $(80 \%)$. Only in 209 cases we did not 
obtain valid measurements with either probe, finally we obtained valid measurements in $93.5 \%$ of cases.

Regarding overweight and obese patients, a total of 2046 patients were examined. In the 1156 overweight patients, reliable LSM were obtained in 1039 (89.9\%) cases: in $729(63.1 \%)$ by the standard M probe and in $310(26.8 \%)$ by the XL probe. In the 890 obese patients, reliable measurements were obtained in 746 patients $(83.8 \%)$, in 164 (18.4\%) by the $\mathrm{M}$ probe, and in $582(65.4 \%)$ by using the XL probe. Thus, by using both probes, reliable measurements were obtained in $1785(87.2 \%)$ of overweight and obese patients.

As expected, the feasibility decreased with the BMI, so that in severely obese patients (BMI $\left.\geq 40 \mathrm{~kg} / \mathrm{m}^{2}\right)$, only $53 \%$ could be evaluated, almost all of them with the XL probe (Table II).

Overall, TE measurements were more feasible in men as compared to women ( $88.6 \%$ vs. $85.4 \%, \mathrm{p}=0.0277)$. Using $\mathrm{M}$ probe, TE measurements were also more feasible in men as compared to women $(47.3 \%$ vs. $38.9 \%, p=0.0349)$,

Table I. Patients' characteristics

\begin{tabular}{ll}
\hline Parameter & \\
\hline Number of patients & 3235 \\
Weight: mean $\left(\mathrm{kg} / \mathrm{m}^{2}\right)$ & $27.8 \pm 4.9$ \\
$\quad$ - normal weight $\left(\mathrm{BMI}<25 \mathrm{~kg} / \mathrm{m}^{2}\right)$ & $1189(36.7 \%)$ \\
- overweight $\left(\mathrm{BMI} 25-30 \mathrm{~kg} / \mathrm{m}^{2}\right)$ & $1156(35.7 \%)$ \\
- obese $\left(\mathrm{BMI}>30 \mathrm{~kg} / \mathrm{m}^{2}\right)$ & $890(27.6 \%)$ \\
Age (years) & $54.1 \pm 13.4$ \\
Gender: & \\
- men & $1495(46.2 \%)$ \\
- women & $1740(53.8 \%)$ \\
Indication for LS assessment: & $574(17.8 \%)$ \\
- Viral B Chronic Hepatitis & $96(3 \%)$ \\
- HBV asymptomatic carrier & $997(30.8 \%)$ \\
- Viral C Chronic Hepatitis & $609(18.8 \%)$ \\
- Nonalcoholic fatty liver disease & $240(7.4 \%)$ \\
- Alcoholic liver disease & $24(0.7 \%)$ \\
- Autoimmune Chronic Hepatitis & $72(2.2 \%)$ \\
- Cholestatic Chronic Hepatitis & $86(2.7 \%)$ \\
- Cirrhosis of unknown etiology & $537(16.6 \%)$ \\
- Other &
\end{tabular}

while using XL probe, TE measurements were more feasible in women as compared to men (46.5\% vs. $41.3 \%)$, but the difference did not reach statistical significance: $\mathrm{p}=0.4845$.

\section{Discussions}

TE has been proven to be a valuable method for staging fibrosis by several meta-analyses [1-4], and is included in the European Guidelines for diagnosis and treatment of chronic hepatitis $\mathrm{C}$ [7].

Knowing the low rate of valid measurements obtained with the $\mathrm{M}$ probe in some population groups (especially in obese and severely obese patients), practical solutions were needed to solve this problem. The XL probe enables the evaluation of patients in whom the $M$ probe was not successful. De Ledinghen et al was the first to show that in severely obese patients $\left(B M I \geq 40.5 \mathrm{~kg} / \mathrm{m}^{2}\right), 10$ valid measurements were obtained only in $45 \%$ of the patients with the M probe and in $76 \%$ of the subjects with the XL probe $(\mathrm{p}<0.001)$ [15]. On the other hand, 59\% of cases with invalid measurements by $\mathrm{M}$ probe, could successfully be evaluated using the XL probe. This was the first step to the introduction of the XL probe in daily practice, especially in obese subjects.

Another study that evaluated a cohort of 276 overweight and obese patients with viral hepatitis or NAFLD, showed that failure to obtain values by TE was $1.1 \%$ using the XL probe and $16 \%$ using the M probe [16]. Reliable measurements were obtained in $73 \%$ of cases by the XL probe vs. $50 \%$ by the $\mathrm{M}$ probe $(\mathrm{p}<0.00005)$. On the other hand, by using the XL probe, $61 \%$ of patients in whom the $\mathrm{M}$ probe was unreliable could be evaluated.

Another observation from this study was that median liver stiffness values using the XL probe were lower than those obtained with the $\mathrm{M}$ probe (6.8 versus $7.8 \mathrm{kPa}$; $\mathrm{p}<0.00005)$ [16]. The same thing was observed in a study from our Department, in which paired measurements were performed with both probes in 98 patients. XL LSM values strongly and significantly correlated with those obtained by

Table II. Feasibility of TE measurements by M and XL probes in overweight and obese patients, according to BMI and gender

\begin{tabular}{llcc}
\hline $\begin{array}{l}\text { Category } \\
\text { (total number) }\end{array}$ & $\begin{array}{l}\text { Reliable measurements } \\
(\%)\end{array}$ & $\begin{array}{l}\text { Reliable M probe } \\
\text { measurements (\%) }\end{array}$ & $\begin{array}{l}\text { Reliable XL probe } \\
\text { measurements (\%) }\end{array}$ \\
\hline Overweight: $\mathrm{n}=1156^{\text {Obese: } \mathrm{n}=890}$ & $1039(89.9 \%)$ & $729(63.1 \%)$ & $310(26.8 \%)$ \\
$\quad-$ grade I obesity $^{1}: \mathrm{n}=666$ & $746(83.8 \%)$ & $164(18.4 \%)$ & $582(65.4 \%)$ \\
$\quad-$ grade II obesity $^{2}: \mathrm{n}=177$ & $-580(87.1 \%)$ & $-143(21.5 \%)$ & $-437(65.6 \%)$ \\
$\quad-$ grade III obesity $\mathrm{3}: \mathrm{n}=47$ & $-141(79.7 \%)$ & $-20(11.3 \%)$ & $-121(68.4 \%)$ \\
Women: $\mathrm{n}=890$ & $-25(53.2 \%)$ & $-1(2.1 \%)$ & $-24(51.1 \%)$ \\
Men: $\mathrm{n}=1156$ & $760(85.4 \%)$ & $546(38.9 \%)$ & $414(46.5 \%)$ \\
\hline
\end{tabular}

$\mathrm{n}$ - number of patients, ${ }^{1}$ grade I obesity: BMI $=30-34.9 \mathrm{~kg} / \mathrm{m}^{2},{ }^{2}$ grade II obesity: BMI $=35-39.9 \mathrm{~kg} / \mathrm{m}^{2},{ }^{3}$ grade III obesity: BMI $\geq 40 \mathrm{~kg} / \mathrm{m}^{2}$ 
M probe (Spearman $r=0.789, p<0.0001$ ), but were significantly lower [median $7.7 \mathrm{kPa}$ (range 3.7-69.1) vs. $6.4 \mathrm{kPa}$ (range $3.1-53.8$ ), Wilcoxon paired t test $\mathrm{p}<0.001$ )] [17]. The same results were obtained by the group of FriedrichRust in a study on 50 patients with NAFLD/NASH who underwent liver biopsy and TE measurements. In their study the median liver stiffness measurement with the XL probe was significantly lower than when using the M probe (6.9 $\mathrm{kPa}$ vs. $8.4 \mathrm{kPa}, \mathrm{p}<0.001)$ [18]. The reason might be that nonhepatic tissue is involved in the measurement with the $\mathrm{M}$ probe in patients with a skin-to-capsule distance greater than $25 \mathrm{~mm}$ [18]. So, it must be taken into consideration that the XL probe can underestimate the severity of fibrosis, and, when in doubt, liver biopsy should be performed.

A drawback of our study is that it is a retrospective one, but it shows real life results of the patients in our area. In daily practice, at least in developed countries, where obesity is a real problem, this large monocentric cohort of patients can be an indication of the utility and feasibility of TE in real life setting. In an area with quite a large proportion of overweight and obese patients (such as ours), the intend-to-diagnose performance of a method is important. In our cohort we can estimate how often we can obtain valid measurements by TE, according to the BMI. Thus, in severely obese subjects, BMI $\geq 40 \mathrm{~kg} / \mathrm{m}^{2}$, from which only $53 \%$ could be evaluated even by XL probe, the use of a biological test (such as FibroTest or FibroMax) can be an alternative for the non-invasive evaluation of fibrosis. Also, another shear wave elastographic method - Acoustic Radiation Force Impulse Elastography - should be taken into consideration, since its feasibility seems to be better [19].

In conclusion, in this large cohort of real life patients, the feasibility of TE with M probe was $62.2 \%$. Reliable measurements, using both $\mathrm{M}$ or XL probes allowed the evaluation of liver stiffness in $93.5 \%$ of all cases and reliable liver stiffness measurements can be obtained in the majority of the obese and overweight patients $(87.2 \%)$.

\section{Conflict of interest: none}

\section{References}

1. Talwalkar JA, Kurtz DM, Schoenleber SJ, West CP, Montori VM. Ultrasound-based transient elastography for the detection of hepatic fibrosis: systematic review and meta-analysis. Clin Gastroenterol Hepatol 2007; 5: 1214-1220.

2. Friedrich-Rust M, Ong MF, Martens S, et al. Performance of transient elastography for the staging of liver fibrosis: a metaanalysis. Gastroenterology 2008; 134: 960-974.

3. Stebbing J, Farouk L, Panos G, et al. A meta-analysis of transient elastography for the detection of hepatic fibrosis. J Clin Gastroenterol 2010; 44: 214-219.
4. Tsochatzis EA, Gurusamy KS, Ntaoula S, Cholongitas E, Davidson BR, Burroughs AK. Elastography for the diagnosis of severity of fibrosis in chronic liver disease: a metaanalysis of diagnostic accuracy. J Hepatol 2011; 54: 650659.

5. Sporea I, Popescu A, Gheorghe L, Cijevschi Prelipcean C, Spârchez Z, Voiosu R. "Quo vadis" liver biopsy? A multicentre Romanian study regarding the number of liver biopsies performed for chronic viral hepatitis. J Gastrointestin Liver Dis 2012; 21: 326.

6. Guéchot J. Non-invasive evaluation of liver fibrosis: More well-validated tests available for patient management. Liver Int 2015; 35: 1643-1645.

7. European Association for the Study of the Liver. EASL Clinical Practice Guidelines: management of hepatitis C virus infection. J Hepatol 2011; 55: 245-264.

8. Castera L, Foucher J, Bernard PH, et al. Pitfalls of Liver Stiffness Measurement: A 5-Year Prospective Study of 13,369 Examinations. Hepatology 2010; 51: 828-835.

9. Şirli R, Sporea I, Bota S, Jurchiş A. Factors influencing reliability of liver stiffness measurements using transient elastography (M-probe)-monocentric experience. Eur J Radiol 2013; 82: e313-e316.

10. Beaugrand, M. Le Fibroscan: mode d'emploi. Gastroenterol Clin Biol 2006; 30; 513-514.

11. Delasalle, P. Le FibroScan Mode d'emploi et Coût. Acta Endoscopica 2007; 37: 400-401.

12. Sandrin L, Fourquet B, Hasquenoph JM, et al. Transient elastography: a new non-invasive method for assessment of hepatic fibrosis. Ultrasound Med Biol 2003; 29: 17051713

13. Bamber J, Cosgrove D, Dietrich CF, et al. EFSUMB Guidelines and Recommendations on the Clinical Use of Ultrasound Elastography. Part 1: Basic Principles and Technology. Ultraschall Med 2013; 34: 169-184.

14. Yatsuya H, Li Y, Hilawe EH, et al Global trend in overweight and obesity and its association with cardiovascular disease incidence. Circ J 2014; 78: 2807-2818.

15. de Ledinghen V, Vergniol J, Foucher J, El-Hajbi F, Merrouche W, Rigalleau V. Feasibility of liver transient elastography with FibroScans using a new probe for obese patients. Liv Int 2010; 30: 1043-1048.

16. Myers RP, Pomier-Layrargues G, Kirsch R, et al. Feasibility and diagnostic performance of the FibroScan XL probe for liver stiffness measurement in overweight and obese patients. Hepatology 2012; 55: 199-208.

17. Şirli R, Sporea I, Deleanu A, et al. Comparison between the $\mathrm{M}$ and XL probes for liver fibrosis assessment by transient elastography. Med Ultrason 2014; 16: 119-122.

18. Friedrich-Rust M, Hadji-Hosseini H, Kriener S, et al. Transient elastography with a new probe for obese patients for non-invasive staging of non-alcoholic steatohepatitis. Eur Radiol 2010; 20: 2390-2396.

19. Bota S, Herkner H, Sporea I, et al. Meta-analysis: ARFI elastography versus transient elastography for the evaluation of liver fibrosis. Liver Int 2013; 33: 1138-1147. 